\title{
Música de Mbira: Lentes e reflexões ampliadoras de conceito(s) e significado(s) da Música
}

\author{
Micas Orlando Silambo \\ Universidade Federal da Paraíba \\ yanikmicas@gmail.com \\ https://orcid.org/0000-0002-4682-043X
}

Resumo: Este trabalho apresenta, discute e propõe, através da Música de Mbira, uma abordagem integrativa como parte da compreensão aberta dos conceitos de músicas em suas dimensões socioculturais. Para isso, tomo como base uma pesquisa bibliográfica em torno dos estudos de (Etno)musicólogos, Antropólogos e afins, articulando com minha observação participante e prática na cultura musical africana. Os resultados apontam para uma compreensão mais consolidada dos conceitos das Músicas abrangendo outros conhecimentos e saberes não sonoros que são estabelecidos, compartilhados e ressignificados musicalmente, culturalmente e socialmente dentro de um grupo específico inserido na sociedade. Reitero que os elementos sonoros não acontecem por si só, eles se articulam por inúmeras motivações e memórias que nos direcionam para o seu papel como produto e processo social que esquematiza situações corriqueiras de uma rede mais ampla de relações humanas.

Palavras-chave: Conceitos de Música, Música de Mbira, Inter-relações socioculturais.

\section{Mbira Music: Magnifying lenses and reflections of the concept(s) and meaning(s) of Music}

Abstract: This work presents, discusses, and proposes, through the Mbira Music, an integrative approach as part of an open understanding of the concepts of music in their socio-cultural dimensions. For this, I take as a base procedure bibliographic research around the studies of (Ethno)musicologists, Anthropologists, and related assumptions, articulating with my participant observation and training experiences in African musical culture. The results point to a more consolidated understanding of the concepts of Music, covering other processes and non-sound processes that are established, shared, and re-signified musically, culturally, and socially within a specific group inserted in society. I reiterate that the sound elements do not happen by themselves, they are articulated by countless motivations and memories that direct us to its role as a product and social process that outlines common situations in a broader network of human relationships.

Keywords: Music Concepts, Mbira's music, Sociocultural interrelationships.

\section{Apresentação e tendências metodológicas}

Este artigo é um recorte de uma pesquisa que está sendo desenvolvida em uma instituição federal de ensino superior. O trabalho apresenta, discute e propõe, através da Música de Mbira, uma abordagem integrativa dos aspectos que ampliam os conceitos de músicas. Para isso, tomo como base uma pesquisa bibliográfica em torno dos estudos da (Etno)musicologia, Antropologia, entre outras áreas, articulando com minha observação participante e prática na cultura musical africana. 
Os dicionários ${ }^{1}$ comumente usados reduzem a música, de forma explícita ou implícita, a "combinação harmoniosa e expressiva de sons"; "arranjo de sons no tempo"; "uma composição musical"; "a arte de se exprimir por meio de sons seguindo regras variáveis conforme a época, a civilização, etc.” Estes conceitos se preocupam em estabelecer elementos óbvios e "sonoros" da música: notas, harmonia, movimentos rítmicos, manipulação de andamento e dinâmica, marcações metronômicas, estruturas tonais e atonais, timbre dos instrumentos, escalas e acordes, formas melódicas, condução vocal, entre outros.

Qualquer um desses elementos, no entanto, pode produzir ou ser articulado expressivamente como sinal sonoro discreto que diz ou contradiz a força de um significado específico tensionando concreta ou abstratamente o sujeito. Então o que os conceitos acima dizem em um ambiente onde a música concretiza a espiritualidade, religiosidade, cura aos doentes, participação ritualística e organização social.

$\mathrm{Na}$ palestra proferida na 29a reunião da International Society for Music Education (ISME), realizada em Beijing, China, o checo Bruno Nettl iniciou a sua mediação de Educação Musical e Etnomusicologia refletindo que "Música é, na terminologia Americana, divertida, agradável, uma coisa para gostar, para amar" (NETTL, 2010, p. 2). Os atributos elencados por este (etno)musicólogo emigrado para os Estados Unidos são, realmente, os esperados pela audiência, mas nem sempre ela recebe uma organização sonora agradável e divertida, pois esta organização tem seu próprio lugar que é refletido pelos papéis que tal estrutura sonora representa em cada cultura.

Para o antropólogo suíço Laurent Aubert (2007, p. 1), "Nós nos identificamos com a música que nós gostamos, porque corresponde à nossa sensibilidade e visão do mundo; mas nos afastamos de outras músicas quando elas são estranhas às nossas afinidades e não nos dizem algo". O prazer musical é, assim, determinado por características individuais, coletivas e ambientais que se cruzam interna e externamente, relativizando ecleticamente o próprio gosto pela música tanto para quem a produz quanto para o receptor que se insere num mundo de pluralidade.

\footnotetext{
${ }^{1}$ Como, por exemplo, Webster's New Collegiate Dictionary (1973), (cf. AMOAKU, 1985).
} 
Devido a essas características, as afinidades musicais são sempre portadoras de significados articulados culturalmente, humanamente, socialmente e espiritualmente. Assim, a música é um conceito que depende da cultura e vice-versa, pois o dinamismo, diversão, gosto e o amor são práticas que dependem de época, espaço, sujeito, situação entre outros aspectos que dão forma, sentido e direção às nossas vidas na sociedade. Evidentemente, "a música como cultura é definida a partir das suas inter-relações, sendo também definidora dos aspectos importantes para a caracterização identitária de uma determinada sociedade" (QUEIROZ, 2005, p. 87).

Refletindo via musicólogo britânico Cook (1990, p. 222), uma cultura musical é essencialmente uma entidade cognitiva, pois ela define as coisas que as pessoas devem saber para entender, executar e criar música aceitável em sua cultura. Trata-se de meios básicos pelos quais a identidade de uma cultura musical é mantida. A música, diz Bohlman (2003, p. 51), representa a cultura como uma forma de expressão comum à humanidade e como uma das manifestações mais extremas da diferença, isto é, ela existe em todas as sociedades de maneira distinta. Este etnomusicólogo oferece-me lentes para dizer que a música é apenas uma linguagem culturalmente universal ao considerar que todas as sociedades ou grupos expressam as suas singularidades através dela, possibilitando uma forma simbólica amplamente inter-relação com a sociedade.

Acelerando o meu posicionamento, os elementos sonoros não acontecem por si só. Eles se articulam por motivações, narrativas e memórias que nos direcionam para um ponto culminante fora do som e para seu papel como produto social que esquematiza situações corriqueiras dentro de uma rede mais ampla de significados socioculturais. Assim, quero argumentar que o conceito de Música deve ser flexível de acordo com o contexto da sua produção. Este argumento é sustentado pela ideia de que as experiências musicais são compreendidas e atribuídas a significados por meio de linguagens e sistemas simbólicos particulares que são sujeitas/os a diferentes tipos de regulação social.

Ao longo deste texto o termo contexto social aparecerá com maior recorrência, a opção se dá por a palavra dimensionar a ampla circulação de seus sentidos sociais como geradoras dos significados da música. Tais contextos, não só intersectam e reforçam as estruturas sonoras, eles são representações fundamentais que refletem e constroem parte significativa da música sem as quais ela não gera sentido algum. Essa abordagem baseia- 
se na premissa de que os materiais sonoros são ouvidos em termos de seu uso e função em contextos sociais e culturais específicos.

Assim, pretendo reduzir a distância da relação música e significados sociais e culturais, para então ampliar os seus conceitos. Estruturalmente, apresento a Música de Mbira e suas inter-relações. Em seguida, discuto os termos "uso e função" como cabaças analíticas ampliadoras.

\title{
1. Música de Mbira e suas inter-relações socioculturais
}

A Música de Mbira $^{2}$, prática tradicional africana muito difundida na região abaixo da bacia do vale do Rio Zambeze ${ }^{3}$, apresenta processos que podem emergir diversos aspectos sociais. O etnomusicólogo sul africano Andrew Tracey em dois textos publicados em 1972 e 1974 pela International Library of African Music fez um rastreamento da origem dos diferentes tipos de Mbira mostrando alguns aspectos sociais vinculados com a sua performance.

Tracey coloca que a Música de Mbira auxilia as cerimônias religiosas dos espíritos ancestrais dos Vakorekore, Vasena ou Vatsonga de Zimbabwe e nos Vatavara e Vanyungwé de Moçambique. Quem aprofunda este posicionamento é o etnomusicólogo americano Paul Berliner por meio de uma pesquisa de campo de cerca de sete anos em Zimbabwe. Para ele a Música de Mbira era mais frequente ser usada em cerimónias de evocação dos espíritos ancestrais dos Vashona designadas mapira (singular bira).

\begin{abstract}
A bira é uma cerimônia formal que dura toda a noite, na qual os membros da família se reúnem para pedir ajuda a um espírito ancestral comum. Durante a cerimônia, o espírito discerne a causa da doença ou infortúnio através da consulta aos aflitos. A família serve bebidas do ritual, especialmente fabricada em homenagem aos antepassados, e convida um conjunto de executantes de Mbira para fornecer a música da noite (BERLINER, 1978, p. 187).
\end{abstract}

A Música de Mbira, por assim dizer, se constitui como parte indispensável da "medicina alternativa" que cura a doença ou remove o mal no paciente.

Esta música pode desempenhar várias funções. A etnomusicóloga zimbabuana Laina Gumboreshumba (2009, p. 31) explorando o fato de ela ter observado e vivenciado

\footnotetext{
2 Instrumento musical.

${ }^{3}$ Uma região que compreende a maior parte da Rodésia do sul (Zimbabwe), sul e centro de Moçambique, sul e leste da Zâmbia, sul do Malawi e norte de Transvaal na África do Sul (TRACEY, 1972, p. 85).
} 
a Música de Mbira inicialmente com o seu pai e depois nos eventos de evocação dos espíritos ancestrais demonstra em sua dissertação de mestrado, pela Rhodes University, África do Sul, que essa prática musical envolve qualquer ocasião ritualística como a indicação ou instalação de um chefe local, oração de pedido de chuva (mukwerera/mafuwe), cerimônia de agradecimento (mapira ekutenda) ${ }^{4}$, festas de bebidas tradicionais destinadas a uma pessoa doente ou uma cerimônia de possessão. Nestas ocasiões é desejável que os executantes de Mbira estejam presentes para tocarem músicas contextuais, em homenagem ao chefe em questão ou a situação do, então, momento.

A música une, por isso, o mundo dos vivos e dos espíritos, atraindo os espíritos mortos. Ela age como um repositório da espiritualidade que é maravilhado para a dimensão dos vivos, renovando o lugar e tempo sagrado à medida que interage profundamente com todas as partes dialógicas da performance. Nessa conexão, o vivo e o morto, o natural e sobrenatural formam elos profundos de uma cadeia significativa na qual reviver os ancestrais traduz uma continuidade da vida em constante mudança. Tal prática cultural envolve os participantes na cerimônia para meditar, estimulando a sua participação incansável na dança, com palmas e cantos que acompanham a música durante a noite (BERLINER, 1978, p. 190).

Os efeitos sonoros peculiares da Música de Mbira produzem um significado social e espiritual exclusivo atribuído através de uma gama de signos e valores típicos dessa cultura, o que leva os vivos a acreditar que suas almas nunca morrem, mas iniciam um novo ciclo de vida eterna para dar comida, vestuário, saúde, música, costumes, etc. aos vivos em uma relação visivelmente invisível. Portanto, o corpo dos performers não é essencialmente formado por ossos e carne e sim de uma alma espiritual corporificada. Estes efeitos são encarados como incorporando uma ação espiritual eficaz, e se tornam o meio de interação que invoca ações participativas de seres sobrenaturais. Nessa linha, o etnomusicólogo nigeriano Meki Nzewi reflete que "as culturas indígenas normalmente reconhecem os papéis significativos e afetivos-efetivos de Deus, os ancestrais e outros seres sobrenaturais na vida pessoal, familiar e comunitária, bem como nas experiências religiosas (NZEWU, 2007, p. 78).

\footnotetext{
4 As expressões entre parênteses se encontram na língua Shona comumente falada no centro de Moçambique e no Zimbabwe.
} 
$\mathrm{Na}$ Música de Mbira a ancestralidade se relaciona também com a reverberação dos processos musicais numa descendência onde etc. trisavó/ô, bisavó/ô, avó/ô, pai/mãe, etc. passam saberes para o outro ou outra num ciclo, geralmente, ininterrupto. Há um ponto onde essa relação musical ocorre com o indivíduo dentro do ciclo de vida que nem sempre é claro para o presente sujeito possuído pelo espírito da música, podendo ser na família nuclear ou extensa, na comunidade ou nos rituais, entre outros pontos.

Esta relação ritualística com a prática musical às vezes leva o fabricante ou executante da Mbira a personificar seu relacionamento com o instrumento como um todo e/ou com as partes deste. Um exemplo a esse respeito pode ser encontrado no estudo do etnomusicólogo moçambicano Lucas Johane Mucavele ${ }^{5}$ que enfatiza o seguinte:

Tradicionalmente, os instrumentos musicais são, geralmente, feitos para uso próprio. Um instrumentista talentoso é aquele que sabe fazer seu próprio instrumento. E, porque os instrumentos são feitos a mão, cada um é único, tendo suas particularidades e identidade. O construtor passa muito tempo em cada instrumento, desenvolvendo assim uma intimidade com ele. Quando um instrumento for pedido, o construtor levará em consideração o tamanho da mão do "solicitante", ou o próprio "solicitante" dará a especificação quanto ao tamanho, a afinação e a tonalidade, se aplicável, para que o instrumento seja personalizado para ele / ela (sua dona). Assim, o dono / comprador participa do processo de construção, o que torna o instrumento pessoal. Então, dependendo das crenças, como o instrumento é levado para casa pela primeira vez, é formal ou informalmente apresentado em sua nova casa, por meio de um ritual, ou, simplesmente, uma performance ${ }^{6}$ (MUCAVELE, 2018, p. 110, tradução minha).

A personificação pode ser vista em várias dimensões. Assim, em segundo exemplo, ao descrever as teclas da sua Mbira, o etnomusicólogo zimbabuano, Dumisani Abraham Maraire, chamou a tecla mais baixa ou grave do instrumento de "pai [- P]"; a tecla uma oitava acima dessa, a "mãe [- M]"; e a tecla uma oitava acima dessa [mãe], a "criança [F]". De acordo com esta estrutura de saber, o restante das teclas compreende quatro "famílias" de teclas semelhantes, cada uma com uma "mãe [- M1, 2, 3 e 4]" e "filho [-

\footnotetext{
${ }^{5}$ Mucavele é também um fabricante, performer e pesquisador da Mbira e outros instrumentos musicais tradicionais africanos.

${ }^{6}$ No original: "Traditionally, musical instruments are, usually, made for self use. An accomplished instrumentalist is one who can make his/her own instrument. And, because instruments are made by hand, each one is unique, having its particularities and identity. The builder spends much time on each instrument, thus developing an intimacy with it. When and instrument is ordered, the builder will consider the size of the "orderer's" hand, or the "orderer" himself, will give specification regarding the size, the tuning and the tonality, if applicable, so the instrument is customized to him/her (its owner).. Thus, the owner/orderer participates in the construction process, which makes the instrument personal. Then, depending of the beliefs, as the instrument is taken home for the first time, it is formally or informally presented to its new home, through a ritual, or, simply, a performance" (MUCAVELE, 2018, p. 110).
} 
F1, 2, 3 e 4]" ou "filhos gêmeos" (duas teclas com a mesma altura). Havia uma tecla no instrumento, [hoje encontrada na Mbira Nyunganyunga], que não pertencia a nenhuma dessas "famílias"; Maraire chamava esta tecla de "ovelha negra [- OV]" ou "nota independente" (BERLINER, 1978, p. 1-2), confira as figuras 1 e 2.

Figura 1: Relação oitavada das lamelas.

Figura 2: Relação de parentesco familiar.

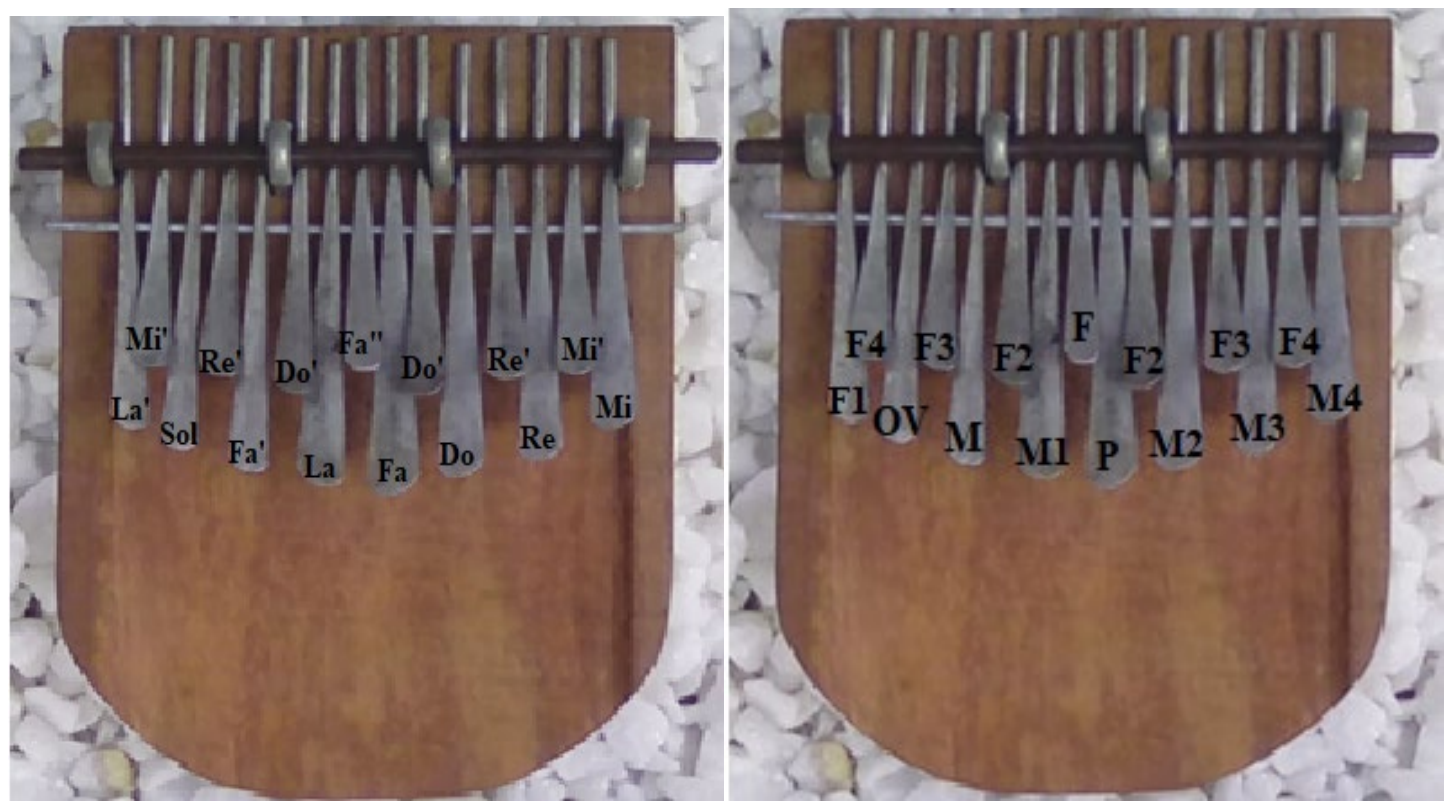

Fonte: Imagem e editoração do autor $(2020)^{7}$. $\quad$ Fonte: Imagem e editoração do autor (2020).

Entendo que a Música revela, através da Mbira, como a maior parte das famílias e grupos sociais africanas/os funcionam: o pai é a peça-chave, a mãe a segunda e os filhos vão se sobrepondo flexivelmente a essa realidade. Essa estrutura não significa, é claro, exercer um poder de autoridade ou silenciamento sobre o outro ou outra afinal todas as lamelas (teclas) são consideradas como membros duma determinada família (várias frequências sonoras da Mbira) que são entrelaçadas ritmicamente, melodicamente e harmonicamente para formarem colaborativamente uma família (uma música) que intervém abertamente em várias situações.

Evidentemente, a Música de Mbira é formada por uma estrutura social bastante complexa. Na província de Maputo, capital de Moçambique, onde venho participando desta cultura musical desde 2008 sinto que fazer Música de Mbira significa também ser

\footnotetext{
${ }^{7}$ Mbira fabricada por Mestre Ivan Johane Mucavele em Maputo, Moçambique em 2018.
} 
íntegro e ativo em diversas atividades desta prática. Ser ativo exige muito tempo, energia e comunicação entre os mestres e outros participantes.

Assim, os mestres e mestras como Beauty Sitoe, Botano Gas, Camada Simango, Ivan Mucavele, Luka Mukhavele, Oziya Makhovo, Xitaro entre outros trabalham ativamente na invenção, fabricação e execução dos instrumentos musicais tradicionais africanos incluindo a Mbira: São agentes importantes no processo de transmissão das experiências colaborativas sobre a música tradicional incluindo dança, teatro, gastronomia; Eles participam semanalmente de performances e jam session formais e informais com seus vestuários de timbre africano devendo cada mestre escolher o momento e nível da sua participação e de envolvimento nessas tarefas que servem como ensaios ou apresentações; Os sujeitos dessa prática musical fazem marketing e comercialização dos seus instrumentos para potenciar seus meios de militância tradicional; São participantes principais em debates, festas, festivais sobre a música tradicional africana-moçambicana remotamente ou fisicamente, entre outras atividades nas quais eles lutam pelas tradições musicais africanas.

Ademais, os mestres são membros da festa de Mbira realizada anualmente em Maputo. Tal festa incorpora uma estrutura de participação aberta onde há uma troca consensual de opiniões, decisões e preferências pessoais sobre o que constitui o ambiente da sua performance o que, a meu ver, motiva os membros a engajar-se de responsabilidades compartilhadas sobre as atividades musicais. Assim, lendo a Música de Mbira por meio da etnomusicóloga Ana Hofman (2020, p. 100) acredito que toda a estrutura da performance "gera sentimentos de realização, interação social, comprometimento e pertencimento" com uma prática musical, cultural, artística e viva. A força dessa cultura musical se expressa por meio do significado de suas produções, vestuários, sujeitos, conversas, costumes, comidas, colares entre outros.

É esse tipo de engajamento que dinamiza esta prática, contudo, o Mestre Ivan Mucavel deixa claro que

ser músico [nesse contexto] não se resume só em cantar bonito! Esse conceito de que só tem que cantar bonito não é nosso [africano]. Foi importado". Ele acrescenta "sou igualmente negacionista de muitos outros 
padrões de pensamento [que] tem muito pouco ou quase nada da contribuição dos povos africanos do Sul [do deserto] de Sahara ${ }^{8}$.

O conceito da negação defendido aqui pelo mestre reflete-se como um elemento fundamental que estimula o exercício criativo típico das performances do corpo africano que chama por abordagens de afirmação e emancipação da negritude por meio de uma descolonização da escuta musical. Portanto,

\begin{abstract}
descolonize a sua escuta - considero [..] ser uma frase mais oportuna para funcionar como slogan nos nossos processos locais de estruturação de [..] abordagens [...] científicas que quase na totalidade atropelam toda a forma legítima africana. Então muito dos formatos musicais que eu identifico estes elementos que arrogantemente exercem a suposta perpetuação da supremacia eurocêntrica sobre as minhas, [...] as quero longe da minha escuta ${ }^{9}$ (MUCAVELE, 2020).
\end{abstract}

Entendo aqui, que o mestre não está contra o conceito das práticas musicais eurocêntricas em si; ele vive-o e dialoga com ele, mas opõe-se aos golpes exercidos sobre o seu conceito de música pelo eurocentrismo clássico. Assim, tomo como minhas as palavras dos mexicanos Chávez e malaio Skelchy (2019, p. 128) ao dizer que "temos que parar de doutrinar os alunos [e outros indivíduos] de que a música da elite europeia é a melhor, é o epítome da evolução humana. Temos que pôr absolutamente um fim nisso".

Estes etnomusicólogos me instigam a pensar que a música acontece em todos os lugares do planeta Terra. Assim, uma escuta e entendimento de música na proposta do mestre Mucavele ensinaria uma ampla variedade de culturas, tradições e seus conceitos. Ressoar esta possibilidade em uma comunidade com distintas pessoas produz resultados e valores emancipatórios que levam os sujeitos a perceber a música de formas alternativas às adotadas pela Arte Ocidental. Nesse sentido, cabe ressaltar outros contextos que costuram as reflexões propostas neste texto estabelecendo outras relações de lugar, tempo e situação de performance.

Primeiro, destaco a pesquisa de campo do antropólogo social e etnomusicólogo britânico John Blacking realizada no Norte de Transvaal, África do sul. Em sua vivência com os africanos o autor observou que na cerimônia de iniciação feminina dos Vavenda da África de Sul, acompanhada pela dança tradicional Domba, a música é um mecanismo para reestruturar as relações sociais (BLACKING, 1973). A prática da música e dança

\footnotetext{
${ }^{8}$ Debate Online pelo Facebook (10, 06, 2020).

${ }^{9}$ Debate Online pelo Facebook (10, 06, 2020).
} 
mais do que simbolizar processos que ocorrem em outras partes da estrutura social dos Vavenda, ela estabelece um afeto que os sujeitos geram na performance.

A produção musical da dança dos Vavenda reúne uma reprodução e transformação da comunidade inteira. Os princípios musicais encontrados em gêneros musicais mais socialmente fragmentados revelam sistemas primários que organizam e informam os aspectos significativos da vida coletiva dos Vavenda, mostrando que um mundo melhor só pode ser formado por combinação não preconceituosa de distintas partes da performance. Neste contexto, as habilidades em música e dança são tão inter-relacionadas que, por exemplo, se um homem dissesse: "Eu posso tocar tshikona", ele queria dizer que também podia dançar, e se uma mulher dissesse "eu danço tshigombela", ela também podia cantar e tocar o tambor" (BLACKING, 1995, p. 234). No entanto, o campo de Musicologia Africana propõe que se amplie essas duas dimensões (dança e música). Os pesquisadores desse campo demonstram que ele tem

\begin{abstract}
o seu objeto [de pesquisa a] (música africana), a composta de canto e dança, reconhecendo simultaneamente a importância de formas de arte aliadas, como artes visuais, teatro e traje. Em suma, o campo de Musicologia Africana deve levar em consideração o contexto do ritual e, além disso, investir na linguagem do fenômeno, incluindo o léxico das culturas performativas da música africana indígena ${ }^{10}$ (MAPAYA, 2018, p. 123).
\end{abstract}

Após o diálogo com John Blacking proponho a pesquisa do antropólogo, etnomusicólogo e linguista Steven Feld desenvolvida na Papua-Nova Guiné, um dos países com maior diversidade cultural no mundo localizado na Oceania. As investigações conduzidas por este americano delineiam que a música funciona como um meio de comunicação para os Kaluli da Papua Nova Guiné (FELD, 1990). Eles aprendem a perceber e sentir a música ligando-a a pássaros, almas, lugares, choros, poesia em um momento de transformação que relaciona os vivos e os mortos.

As músicas, cuidadosamente compostas e ensaiadas, são orientadas a deixar os ouvintes tristes e nostálgicos, levando-os às lágrimas. Neste contexto, como indica Feld (1990, p. 215-217), o ato de levar o público às lágrimas é marcado socialmente pela

10 In this regard, the discipline of African Musicology should be more musicological than ethnomusicological, with its object (African music) being the compound of song and dance, while simultaneously acknowledging the importance of allied art forms such as visual arts, drama and costume. In brief, the discipline of African Musicology should take into cognisance the context of the ritual, and moreover invest in the language of the phenomenon, including the lexicon of indigenous African music performative cultures (MAPAYA, 2018, p. 123). 
retribuição instantânea de queimar as costas do dançarino, uma marca que ele usa para toda a vida. Essas marcas corporais, a meu entender, expressam formas de saberes que levam o sujeito a ser aceite dentro do grupo social atualizando, por consequências, o poder de exercer certos papéis na sociedade.

Portanto, o conceito de música nos Vavenda, Kaluli, Vashona, Vakorekore, Vasena, Vatsonga, Vatavara e Vanyungwé provavelmente, será mal entendida se ele for comparado com outros tipos de música antes de ser analisado como uma expressão simbólica das singularidades determinadas e mediadas culturalmente no seio desses grupos. Neles, a "boa música" depende do sucesso da festividade, cura do doente, a eficácia comunicativa com os espíritos, entre outros aspectos.

Assim, a música é estabelecida como um elemento "que unifique os sujeitos e suas representações em uma expressão coletiva (RIBEIRO, 2017, p. 336). Tais representações denotam elementos típicos de cada manifestação cultural que, apesar de serem distintos, apontam para um espaço de interação social não necessariamente sonoro. Assim, ao conceituar e analisar socialmente a música é preciso estabelecer relações recíprocas entre som, sujeitos, valores, grupos sociais, identidades, circunstâncias, gerações e locais para melhor entender o uso e função que evidencia o seu real significado.

\section{Uso e função como cabaças de significados da música}

Na Música de Mbira as cabaças naturais são usadas com três propósitos: 1) produzir um timbre característico e identitário para cada instrumentista; 2) esconder os dedos do executante de Mbira para que os outros não possam copiar a sua técnica de execução ou música; e 3) ampliar a sonoridade do instrumento de modo a abranger maior número de ouvintes. Neste texto, as cabaças são ampliadoras e impressoras do significado, entendendo que uma discussão conceitual sobre o uso e função pode clarear o papel das inter-relações contextuais que a música tem com as suas dimensões mais amplas dentro da sociedade.

É fundamental que toda a música, incluindo a clássica erudita, seja uma prática social e culturalmente construída e compreendida, pois ela permanece igualmente importante como um meio de reverberação de hábitos e forma de sociabilidade, mas para que isso aconteça adequadamente, devemos reconhecer que: 
todas as músicas são iguais. Cada mundo cultural tem desenvolvido música que serve às suas necessidades. E, cada cultura submete-se a modernização, ela toma o que ela deseja e necessita de outras músicas com as quais têm contato, combinando, sintetizando, mesclando, e tudo isto é a nova autenticidade (NETTL, 2010, p. 8).

A música ao servir às autenticidades pontuais responde de forma flexível e mutável às diversas dimensões e significados sociais em todas as sociedades. A igreja, salão de festas, a corte, a rua, o lar comum, no ritual, o campo de diversas atividades representam lugares onde a música é ativamente criada por quase todos, e sua produção musical, principalmente no contexto africano, sempre foi uma parte normal da vida cotidiana.

"Nunca foi descoberta uma sociedade sem música. Mas, embora fazer música seja uma característica universal da sociedade humana, não é de forma alguma realizada universalmente por todos os indivíduos dentro de uma sociedade" (GREEN, 2003, p. 268). Uma música que tem um papel complexo em uma dimensão social pode desempenhar um lugar básico em outra, ou seja, ela é simultaneamente capaz de ter muitos significados em diferentes lugares e tempos, pois

o que parece ter o mesmo uso social, em duas sociedades pode ter diferentes funções nessas duas sociedades. [...] Em outras palavras, de forma a definir o uso social, e, portanto, fazer uma comparação válida entre os usos de diferentes pessoas ou períodos, é necessário considerar não meramente as formas do uso, mas, também a sua função (MERRIAM, 1964, p. 211).

A função ressalta as motivações que levam os indivíduos a incorporarem a música na sua prática diária enquanto o uso destaca a situação específica onde esta música é aplicada em um determinado grupo social. Por isso, “[...] o 'uso' refere-se às situações na qual a música é aplicada na ação humana; enquanto a 'função' concerne às razões para a sua aplicação [...]" (MERRIAM, 1964, p. 210). Entendo que há uma grande interconexão entre esses dois termos, ou seja, os usos e funções encontram-se, na prática real, intrinsecamente ligados.

Um uso, que é uma ação ou situação (de cura, funeral, pedido de chuva, indicação do chefe), só será considerado uso no momento em que for atribuído razões ou motivos para a sua realização (existência de uma pessoa doente, falecimento de um sujeito, extensão do período de seca ou fome, ocorrência de práticas desordenadas nas comunidades) - ou seja, funções específicas à um determinado contexto de uso social. $\mathrm{O}$ mesmo vale para a função: as razões ou motivos de uma determinada prática acontecem imediatamente a ação ou situação, ao ponto que a função se materializa paralelamente ao 
uso. Existe, em realidade, qualquer base para separar o uso e a função ou será que essa divisão não passa de um artifício de nossos próprios procedimentos analíticos?

O meu professor de História de Música, o etnomusicólogo moçambicano Eduardo Lichuge até prefere que usemos apenas um deles e agregar o outro em nossa opção. Pode ser que isso tenha algum sentido, pois dentro de contextos africanos a música, dança, teatro, vestuário, gastronomia, ginga são pensados como partes interativas e articuladas de um único sistema social não claramente hierárquico e divisório, algo que possa justificar a condensação da situação e razão da música na ação humana. Contudo, penso que tal divisão terminológica das expressões "uso e função" se faz necessária dentro de um contexto de pesquisa, pois nos favorece diversas pistas de vivência, observação, obtenção, interpretação, conceituação e análise das culturas musicais.

Portanto, a distinção é somente analítica. Ela é útil, na análise, por permitir a aplicação de um procedimento prático que distingue aqueles aspectos que parecem mais objetivos (usos) diante dos subjetivos (funções). Ao considerar este procedimento analítico na pesquisa criamos condições abstratas (categorias, classificações e quadros de referência da cultura), que nos possibilitam pensar as relações estruturais reais de uma prática musical. Portanto, defende Stuart Hall,

para pensar ou analisar a complexidade do real, é necessária a prática do
pensar e isso requer o uso do poder da abstração e análise, a formação de
conceitos com as quais se pode recortar a complexidade do real, com o
propósito de revelar e trazer a luz as relações e estruturas que não podem
se fazer visíveis ao olhar nu e ingênuo, e que também não podem se
apresentar nem autenticar a si mesmas (HALL, 2003, p. 150).

Nessa perspectiva, o uso, seja uma festa, festival, encontro, evento, é fácil de percebê-lo por meio visual (pessoas, objetos, panfletos, estrutura do espaço, e por aí vai) que circulam o ambiente onde a situação está ocorrendo. A função, por outro lado, consiste de processos que requerem um enfoque por parte do pesquisador, perguntando, respondendo ou se envolvendo diretamente com as nuances que justificam a realização de tal cerimônia ou situação. A função é frágil por natureza e, consequentemente, muito mais vulnerável a outras interpretações, pois algumas vezes depende do que a pessoa vai experimentando e sentindo no meio social. As pessoas, às vezes, acreditam que um determinado ritual cura (uso) quando realmente os ritos passados culminam com a sua razão efetiva (função). 
Nessa linha, o significado musical envolve uma função no sentido intrínseco do "uso que membros de alguma comunidade impõem ao objeto [sonoro ou não sonoro]" (FAULKNER; RUNDE, 2013, p. 807). Tal objeto adquire uma forma que misturado com a situação estrutura as características e capacidades necessárias para executar a função (razão) que por consequência define a identidade do uso (situação) para a pessoa, como se esses termos fossem um ciclo que ganha uma metamorfose ou mutação irregular em algum lugar.

Compreendo por meio de Faulkner e Runde, que a função social de uma música vincula-se com o "papel" que o objeto desempenha dentro de uma comunidade, enquanto a estrutura se refere à ordenação lógica e interações de diferentes materiais específicos que, por sua vez, delineiam um significado social particular nos sujeitos. Apesar destas metamorfose e me apoiando em Blacking enfatizo que as situações e razões das práticas musicais na sociedade são decisivas na promoção e proibição das habilidades musicais, afetando a escolha de conceitos, princípios e materiais com os quais os sujeitos compõem e estruturam a sua cultura musical. Assim, "qualquer música pode funcionar em qualquer contexto cultural, se, é claro, for do interesse de produtores e consumidores fazê-lo" (BOHLMAN, 2003, p. 47).

Portanto, a música, por sua forte e determinante relação com a cultura e a sociedade, ocupa dentro de cada grupo humano um importante espaço com significados, valores, usos e funções que a particularizam de acordo com cada contexto (MERRIAM, 1964). $\mathrm{Na}$ forma de interações humanas que são moldadas por formas de entendimento contextuais, a música particulariza as características de cada manifestação cultural, desenvolvendo sua linguagem específica, uma estrutura rítmica, harmônica ou melódica específica, e assim por diante, que levam o indivíduo à aquisição de competência esperadas para lidar com a performance musical, enquanto se forma como um ser humano aceite na sociedade. Se os elementos da música são constituídos nessa teia contemplativa, entendo que as suas características definidoras precisam incorporar a expressão sonora como um significado difundido e confundido social e culturalmente com elementos não sonoro.

Por isso, não podemos ignorar a cultura e a sociedade no conceito da música. Portanto, uma prática musical constitui um espaço cultural no qual vários processos 
musicais coexistem entre si e interagem com diversos parâmetros que se estabelecem, cruzam - se, fertilizam-se e transformam-se mediante a realidade vivida no seu grupo ou sua sociedade. O conceito da música precisa ser pensado cada vez mais no cerne da última cabaça, ou melhor, dessas interações dos grupos ou códigos socioculturais que ampliam o significado e conceito musical suficientemente justos. A música não é significativa como "música" em si, mas porque nos revela sobre os processos socioculturais que constituem uma sociedade e como tal sua interpretação deve atender também a referências e códigos mais amplos.

\section{Considerações finais}

Comecei este artigo com os conceitos de música que se concentram no plano sonoro. Ao longo do texto fui demonstrando que é relevante articular os elementos musicais sonoros e não sonoros. Assim, o conceito de Música pode ser localizado na interação dos dois planos musicais e nos significados que tais planos evidenciam dentro de um grupo social particular. Dito isso, o significado musical carrega seu caráter socialmente construído como parte de conteúdo que dinamiza o cotidiano num determinado espaço, época ou ocasião.

Portanto, mantenho o argumento principal de que “[...] a música é criada, circulada, reconhecida e respondida de acordo com uma gama de pressupostos conceituais e atividades analíticas que se baseiam em relações sociais, atividades políticas e culturais bastante particulares"11 (NEGUS, 1997, p. 4). Assim, as práticas musicais dependem de interações socioculturais que atravessam um espaço mais abrangente do que a "miniatura" imediatamente ocupada pelos músicos. "Em outras palavras, a experiência musical não pertence apenas ao trabalho musical, compositor ou 'especialista' credenciado, mas também, crucialmente, ao público variado" (FINNEGAN, 2003, p. 188).

Não à toa, os sujeitos usam a música para organizar grupos sociais, articular crenças religiosas e práticas tradicionais, efetivar cerimônias e rituais, acompanhar os momentos

\footnotetext{
11 [...] music is created, circulated, recognized and responded to according to a range of conceptual assumptions and analytical activities that are grounded in quite particular social relationship, political and cultural activities (NEGUS, 1997, p. 4).
} 
de cura, pedido de chuva, indicação de chefe entre outros aspectos socioculturais. É assim que sempre foi pelo menos no continente Africano. Se reconhecermos que a música é uma construção social e cultural, então sua compreensão também deve ser feita em conexões com grupos sociais e culturais, não podendo ser plenamente entendido ou reduzido a uma análise de aspectos isolados. Tudo o que estes aspectos representam em termos de ação, objeto, filosofia e suas consequências é sempre social, um social que não pode ser reduzido ou crucificado a um exame individual. Precisamos estabelecer consistentemente as inter-relações contemplativas de música, cultura e sociedade, pois ao ignorar essa relação esvaziamos o poder compreensivo sustentado pela sua interação recíproca.

Portanto, ao tentar desenhar um conceito de música devemos invocar "[...] um relativismo cultural no qual todas as músicas têm uma pretensão legítima de serem entendidas: primeiro nos termos que sua própria cultura os entende e depois nos termos da sua contribuição para a nossa compreensão da música como um fenômeno mundial" (TITON, 2003, p. 176).

Assim, feito esse percurso, lanço cruzamentos do saber e conhecimento fundamentando que os diversos contextos sociais são elementos potenciais para orientar os conceitos e significados das músicas. Aprendi que, o conceito de música não pode ser reduzido a alguma coisa simples e sintética, pois ele, pelo fato de estar ligado a diversos significados particulares, possui várias objeções polissêmicas que as considero mais brevemente: A música 1) é um conjunto de elementos estruturados (sons, sujeitos, palavras, meios, etc) que direcionam socialmente, culturalmente, religiosamente, espiritualmente e humanamente às nossas vidas na sociedade; 2) é uma caracterização identitária de um conjunto específico de padrões singulares de comportamento aprendido dentro de um grupo social; e 3) é um meio simbólico de organização, comunicação, interação e transformação social que unifica, colaborativamente, os sujeitos.

A principal proposta sugerida aqui é a construção de conceitos mediados principalmente por meio de uma ampla diversidade de contextos sociais. Não proponho um conceito de música, mas ao contrário, suas pluralidades exploradas em múltiplas possibilidades e diversidades que ampliam o respeito e a compreensão da diferença. Consequentemente, a música pode ser definida como uma expressão e apropriação 
sociocultural infinita que responde flexivelmente a várias dimensões da sociedade através de um conjunto de elementos tipicamente codificados. Portanto, a música caracteriza-se com "raízes no som e no movimento, heterogeneidade de significados, uma base na interação social e um significado personalizado, juntamente com uma aparente ineficácia. A música incorpora, entra e transpõe intencionalmente o tempo no som e na ação" (CROSS, 2003).

É preciso fundamentar a relação entre o material musical e significado sociocultural, insistindo num conceito no qual a música necessita de uma gama variáveis que começa, imprecisamente, dos dispositivos de som, segue para a sua organização e estruturação significativa, até alcançar às condições socioculturais, as vezes conflituosas, a partir das quais a música se origina. Digo conflituosa e imprecisa porque pode começar de uma condição sociocultural e no final incorporar o som.

Em qualquer caso, para que algo seja determinado ou aceito como prática musical em um contexto cultural é preciso que combine elementos como sentidos, conceitos, sons, valores, costumes e significados que determinam o seu reconhecimento como expressão sonora. Tais elementos podem ser considerados universalmente existentes em todas as músicas, mas a fórmula, técnica, estrutura, dinâmica, método e teoria da sua produção sonora ou estética apresentam características particulares definidas em cada contexto cultural.

Compreender o conceito de música a partir de interfaces diversificadas pode levar os (etno)musicólogos, compositores, educadores e a sociedade a repensar os "limites sonoros estéticos" que têm base da caracterização do conceito de música na Arte Ocidental. Essa abordagem, se bem que ainda não está consolidada nela, exigirá uma atenção especial não apenas aos gêneros canônicos que têm definido os limites dos campos de estudo, mas a todas as práticas musicais do mundo com suas peculiaridades e contextos.

Nesses últimos parágrafos observo que o conceito de música construa, combine e colide vibrações sonoras a quatro elementos básicos: um aspecto integrante da interação humana; a experiência de produzir, perceber e responder a produção sonora; a transmissão de significados e valores socioculturais; o envolvimento e implicação na construção de identidades afetivas, motoras, cognitivos da personalidade humana. 
Assim, assumo o desafio de estabelecer outros diálogos que ressaltem culturas musicais africanas como Xigubu, Makwayela, Ngalanga, Tufo, Mapiko, Zore, Timbila, Mutimba, Xingomana, Xingombela, Nyau, Makhwayi, Marrabenta, Mandowa, Kateko, Ndokodo, Mutute, Mutchongoio, Mafuwe, Ndjole, Nyambaro, Chiwere, entre outras práticas. Acredito que a pesquisa sobre práticas musicais em todo o mundo pode ser importante para uma melhor compreensão da humanidade.

\section{Referências}

AMAOKU, W. Komla. Toward a Definition of Traditional African Music: A look at the Ewe of Ghana. More than Drumming: Essays of African and AfroLatin American Music and Musicians. Edited by Irene V. Jackson. Westport: Greenwood Press, p. 31-39. 1985.

AUBERT, Laurent. The music of the other: new challenges for ethnomusicology in a global age. Traduzido por Carla Ribeiro. Aldershot: Ashgate, 2007.

BERLINER, Paul. The soul of Mbira: music and traditions of the Shona people of Zimbabwe. Berkeley: University of California Press, 1978.

BLACKING, John. How musical is man? Seattle: University of Washington Press, 1995b, 5 ed. [1973]. $116 \mathrm{p}$.

BLACKING, John. Music, culture \& experience: selected papers of John Blacking. Edited by Reginald Byron; with foreword by Bruno Nettl. Chicago, USA: University of Chicago Press, 1995.

BOHLMAN, Philip Vilas. Music and Culture: Historiographies of Disjuncture. In: CLAYTON, Martin; HERBERT, Trevor; MIDDLETON, Richard (ed.). The cultural study of music: a critical introduction. New York: Routledge. 2003, p. $49-60$.

CHÁVEZ, Luis. SKELCHY, Russell P. Decolonization for Ethnomusicology and Music Studies in Higher Education. Action, Criticism, and Theory for Music Education. Sep. 2019, v. 18, n. 3, p. 115-43. Disponível em: https://doi.org/10.22176/act18.3.115. Acesso em: 10 de Junho de 2020.

COOK, Nicholas. Music, imagination and culture. Oxford: Clarendon Press. 1990.

CROSS, Ian. Music and Biocultural Evolution 19. In: CLAYTON, Martin; HERBERT, Trevor; MIDDLETON, Richard (ed.). The cultural study of music: a critical introduction. New York: Routledge. 2003, p. 24-35.

FAULKNER, P.; RUNDE, J. Technological objects, social positions, and the transformational model of social activity. MIS Quarterly, v. 37 n. 3, 2013, p. 803-818.

FELD, Steven. Sound and sentiment: Birds, weeping, poetics and song in Kaluli experience. 2ed. Philadelphia: Univ. of Pennsylvania Press. 1990. 
FINNEGAN, Ruth. Music, Experience, and the Anthropology of Emotion. In: CLAYTON, Martin; HERBERT, Trevor; MIDDLETON, Richard (ed.). The cultural study of music: a critical introduction. New York: Routledge. 2003, p. 185-196.

GREEN, Lucy. Music Education, Cultural Capital, and Social Group Identity. In: CLAYTON, Martin; HERBERT, Trevor; MIDDLETON, Richard (ed.). The cultural study of music: a critical introduction. New York: Routledge. 2003, p. 268-277.

HALL, Stuart. Da diáspora: Identidades e mediações culturais. Tradução Adelaine La Guardia Resende, et al. Belo Horizonte: Editora UFMG, 2003.

HOFMAN, Ana. Disobedient: Activist Choirs, Radical Amateurism, and the Politics of the Past after Yugoslavia. The Society for Ethnomusicology, v. 64, No. 1, 2020. Disponível em: https://www.jstor.org/stable/pdf/10.5406/ethnomusicology.64.1.0089.pdf. Acesso em 06 de junho de 2020.

MAPAYA, Madimabe Geoff. Dipsticking the Study of Indigenous African Music from the John Blacking Era into the 21st Century. Pretoria: Centre for Advanced Studies of African Society. 2018.

MERRIAM, Alan Parkhurst. The anthropology of Music. Chicago, USA: Northwestern University Press, 1964.

MUCAVELE, Lucas Johane. Applied organology: challenges and potentials of traditional musical instruments in present-day contexts: Xizambi, Ximbvokombvoko, and Mbira. África [s] - Revista do Programa de Pós-Graduação em Estudos Africanos e Representações da África, v. 5 (9), p. 97-116, 2018. Disponível em: https://web.archive.org/web/20200805232819/http://www.revistas.uneb.br/index.php/africas/art icle/download/5430/3425 Acesso em: 21 Set 2020.

NEGUS, Keith. Popular Music in Theory: An introduction. England: Wesleyan University Press. 1997.

NETTL, Bruno. Music Education and Ethnomusicology: A (Usually) Harmonious Relationship. Min-Ad: Israel Studies in Musicology Online, Ramat-Gan, Israel, v. 8, n. 1, p. 1-9, 2010. Disponível em: < http://www.biu.ac.il/hu/mu/min-ad/index.htm>. Acesso em: 17 Janeiro 2019.

NZEWI, Meki. A CONTEMPORARY STUDY OF MUSICAL ARTS: Informed by African Indigenous knowledge systems. Pretoria: Centre for Indigenous Instrumental African Music and Dance (CIIAMDA). 2007. Volume 2.

RIBEIRO, Fábio Henrique Gomes. Performance musical na cultura popular contemporânea de João Pessoa/PB/. Fábio Henrique Gomes Ribeiro. - João Pessoa. 2017, 406f. Tese (Doutorado em Música) Programa de Pós-Graduação em Música da Universidade Federal da Paraíba. 2017.

TITON, Jeff Todd. Textual Analysis or Thick Description? In The cultural study of music: a critical introduction. Editado por CLAYTON, Martin; HERBERT, Trevor; MIDDLETON, Richard. New York: Routledge. 2003. p. 175-184. 
RevistaMúsica, v. 20 n. 2 - Dossiê Música em Quarentena Universidade de São Paulo, dezembro de 2020 ISSN 2238-7625 